

\title{
A reassessment of explanations for discordant introgressions of mitochondrial and nuclear genomes
}

Timothée Bonnet, Raphaël Leblois, Francois Rousset, Pierre-André Crochet

\section{To cite this version:}

Timothée Bonnet, Raphaël Leblois, Francois Rousset, Pierre-André Crochet. A reassessment of explanations for discordant introgressions of mitochondrial and nuclear genomes. Conférence Jacques Monod: Coalescence des approches théoriques et expérimentales en génomique évolutive et biologie des systèmes, Oct 2016, Roscoff, France. hal-02932269

\section{HAL Id: hal-02932269 \\ https://hal.inrae.fr/hal-02932269}

Submitted on 7 Sep 2020

HAL is a multi-disciplinary open access archive for the deposit and dissemination of scientific research documents, whether they are published or not. The documents may come from teaching and research institutions in France or abroad, or from public or private research centers.
L'archive ouverte pluridisciplinaire HAL, est destinée au dépôt et à la diffusion de documents scientifiques de niveau recherche, publiés ou non, émanant des établissements d'enseignement et de recherche français ou étrangers, des laboratoires publics ou privés. 


\section{Motivation}

Examples of massive mitochondrial introgressions combined with no or very limited nuclear introgressions (i.e. mito-nuclear discordance) are accumulating, stimulating the development of various hypotheses to explain this pattern. On the one hand, selective hypotheses propose a selective advantage of the introgressing mitochondrial variants, or counter-selection of the nuclear genome; On the other hand, neutral hypotheses invoke sex-biased processes and/or drift and/or spatial invasions. The neutral hypotheses however are mostly verbal and have not been quantitatively evaluated. Here we reassess all these hypotheses using simulations under a wide range of demographic and genetic scenarios.

\section{General simulation settings}

- Spatially explicit simulations of a secondary contact:

2 habitats, each with $15 \times 10$ demes of $\mathrm{N}=10$ diploid adult pairs $\left(N_{1}=N_{2}=3,000\right)$

Forward individuals-based simulations of 6,000 generations of secondary contact considering spatially limited dispersal (IBD), sex-biased processes, spatial invasion, and selection

Standard coalescent to simulate 80,000 generations of divergence between the ancestral populations

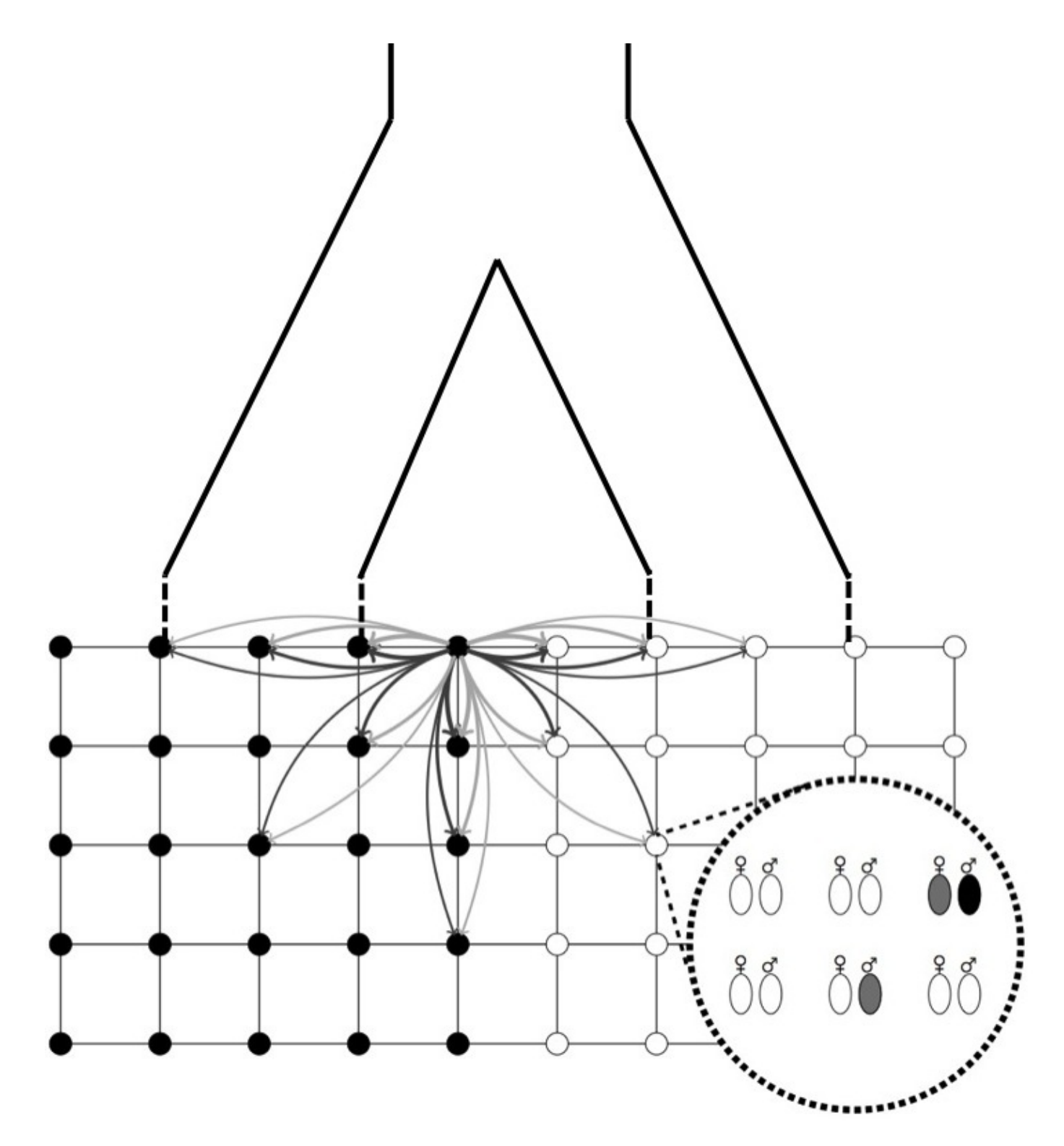

- Multi-locus nuclear genome:

One chromosome with 20 pairs of loci ( 1 neutral \& 1 selected)

Recombination within and between pairs of loci

- Mitochondrial genome:

One chromosome with one pair of linked loci (1 neutral +1 selected)

- Local adaptation is modeled with one nuclear "speciation" locus (proxy for many co-adapted loci in LD):

$\triangleright$ Lower fitness in the non-original habitat

$>$ Lower fitness for hybrids in both habitats

Additional demographic and genetic processes explored

\section{- Sex-biased processes:}

asymmetric crosses: one sex is preferred by both taxa

e.g. the female cow in the Bison/Cow example

sex-specific dispersal: one sex disperses more than the other

sex-specific survival: one sex has higher mortality than the other

\section{- Spatial invasion combined with sex-biased dispersal:}

$>$ One habitat expands over the other after secondary contact, gradually but completely.

Direction and strength of sex-biased dispersal varies among different scenarios

- Strong drift (single hybridization event in small populations):

Only $3 \times 10$ demes in each habitat $\left(N_{1}=N_{2}=600\right)$

Single inter-taxa mating event allowed between two pure individuals

Then no restrictions on matings between hybrids

$>$ No sex-biased processes

For all scenarios, we considered both high (0.1) and low migration rates $(0.001)$

\section{Outputs of the simulation study: introgression measures}

$M$ : proportion of introgressed $\mathrm{Mt}$ copies in the most introgressed taxon

a: vector of proportions of introgressed nuclear gene copies

We are mostly interested in the following output:

$\checkmark M-\overline{\mathbf{a}}$ the mito-nuclear introgression discordance

and we define a Massively Discordant Mitochondiral Introgression

(MDMI) when $M-\overline{\mathbf{a}}>0.8$

\section{Results}

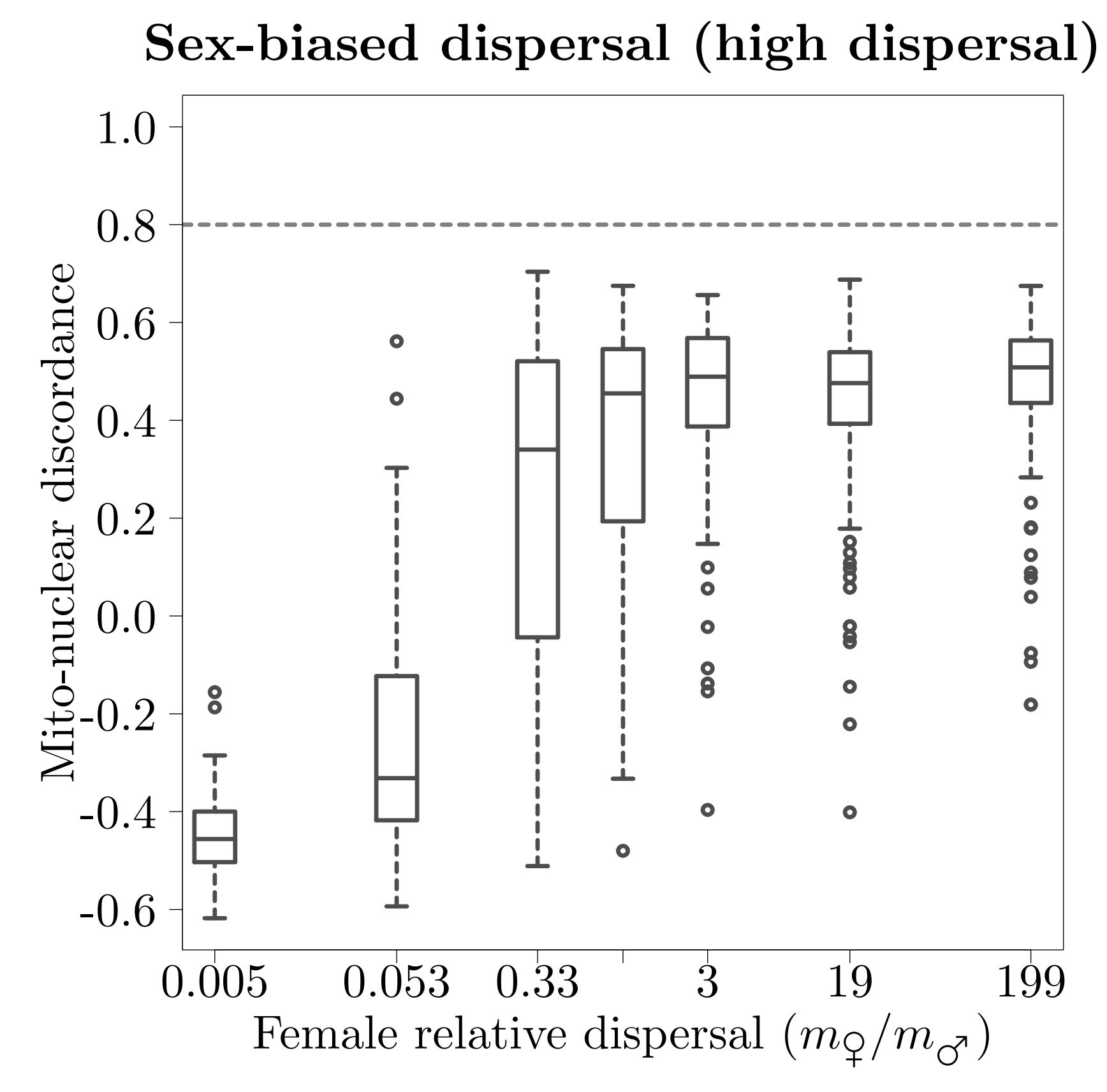

All sex-biases combined (high dispersal)

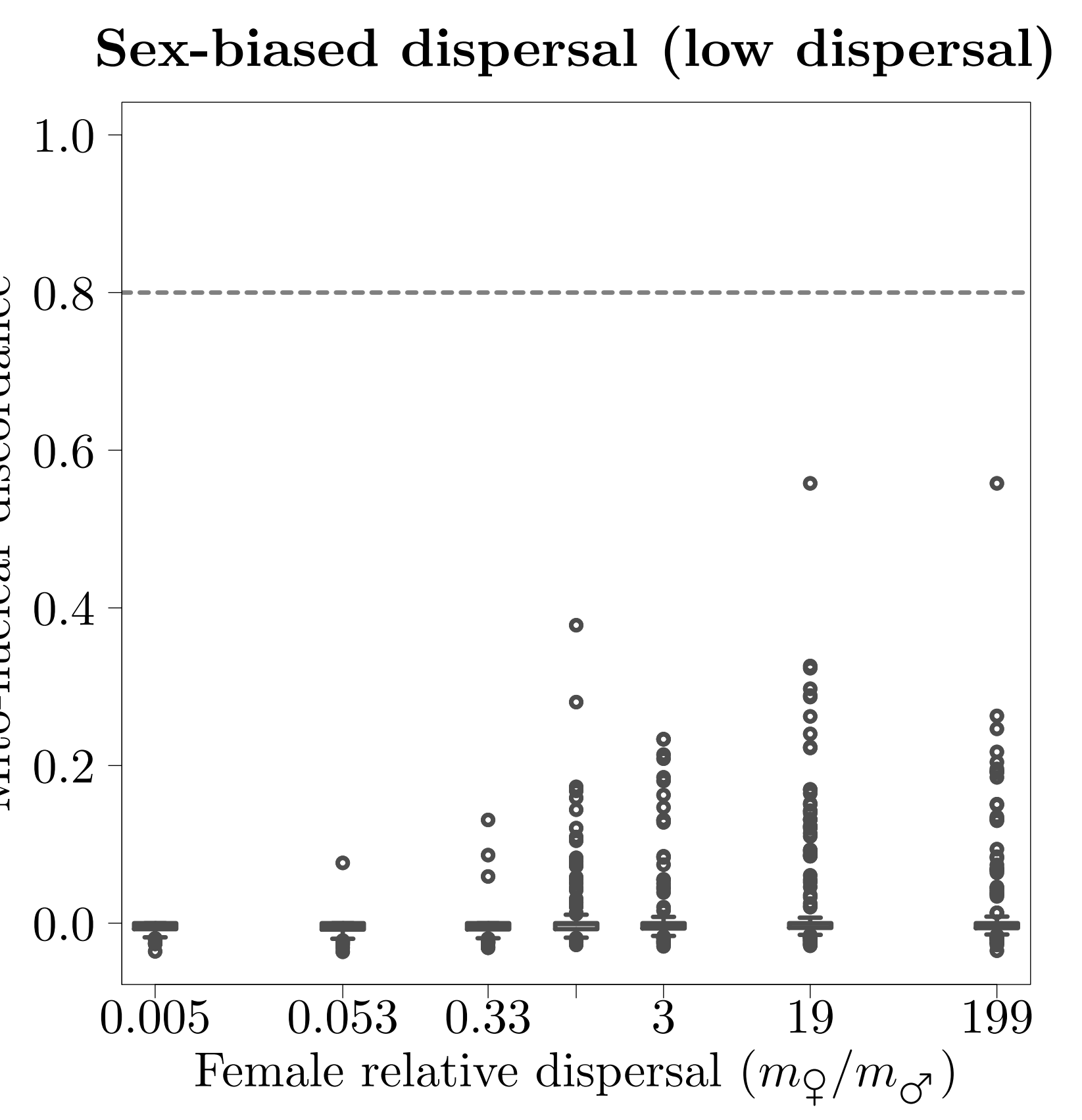

All sex-biases combined (low dispersal)
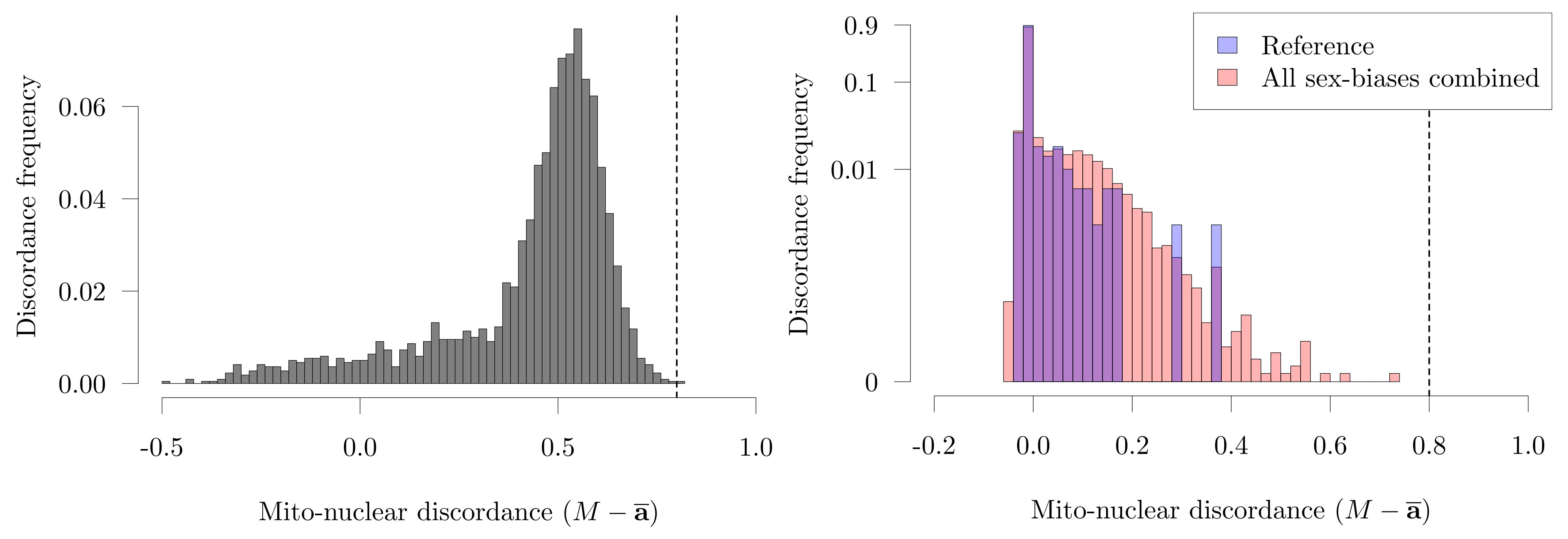

Mito-nuclear discordance $(M-\overline{\mathbf{a}})$

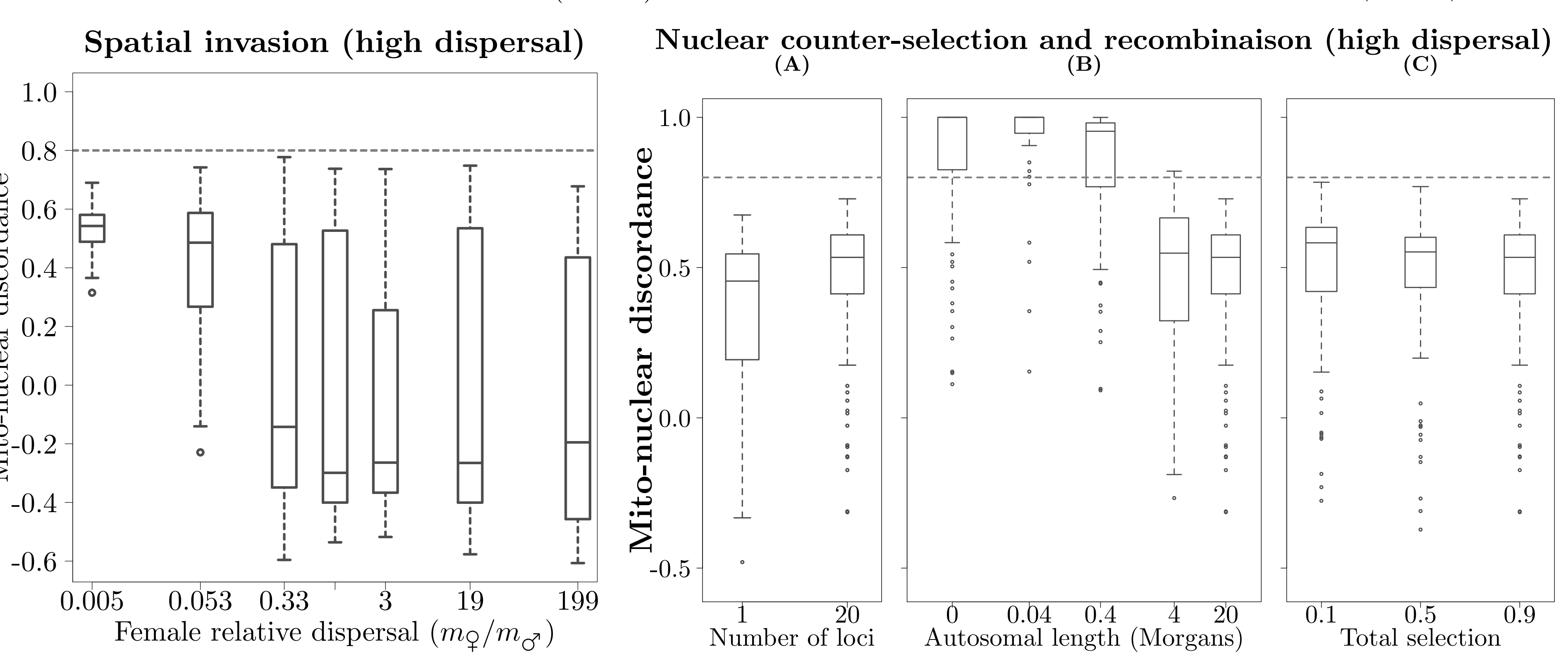

Conclusions

\begin{tabular}{cccccc}
\hline Gene flow & Sex-biases & Invasion & Nu Selection & Mt Selection & MDMI \\
\hline \multirow{4}{*}{ High } & - & - & - & - & No \\
& Yes & - & - & - & No ${ }^{1}$ \\
& - & Yes & - & - & Yos \\
& - & - & - & - & Yos \\
\hline \multirow{2}{*}{ Low } & - & - & - & - & No \\
& Yes & - & - & - & No \\
& - & Yes & - & Yes & No \\
& - & - & - & Yes \\
\hline Single hybridization & - & - & - & - & No $^{2}$ \\
\hline
\end{tabular}

- Neutral processes (sex-biases, strong drift and spatial invasion) fail to explain MDMI

- Only positive selection on $\mathrm{Mt}$ with low migration rates or counter selection on the whole nuclear genome can create MDMI

- but no detection of positive selection using Tajima's D or Fu' Fs on Mt polymorphism observed in the introgressed taxon

Take home message

- Neutral processes can't dissociate nuclear and mitochondrial introgression... .... because females too have nuclear genes!

- Our results are in line with recent and increasing evidence that selection on Mt DNA may be common

- Beware of verbal models, do not trust but test them using models 